\title{
Demarcando espaço para as mulheres na ginástica artística com magnésio: \\ a consolidação das barras assimétricas entre os anos de 1952-1964
}

\section{RESUMO}

As ginastas começaram a competir na GA nas primeiras décadas do Século XX, quando o sistema ideológico de gênero ditava os papeis e os valores da mulher e, consequentemente, o que ela poderia ou não fazer na sociedade e no esporte. $\mathrm{O}$ intuito desse estudo foi lançar luz sobre a consolidação dos aparelhos oficiais no formato competitivo da GA feminina, por meio da análise das barras paralelas assimétricas, um aparelho inicialmente adaptado da categoria masculina. Percebe-se que, ao longo do tempo, as mulheres foram subjugadas ao discurso médico e social que direcionava o uso de seus corpos no cerne da modalidade e na sociedade. Mas, por meio de passos pequenos e do desenvolvimento imposto pelas próprias atletas, houve a necessidade de se construir um aparelho próprio que, simbolicamente, revela que as mulheres queriam ditar os direcionamentos da GA feminina nos seus próprios termos.

PALAVRAS-CHAVE: Aparelhos de ginástica; Mulheres no esporte; Jogos olímpicos
Mauricio Santos Oliveira

Doutor

Núcleo de Pesquisa em Ginástica (NPG),

Universidade Federal do Espírito Santo, Vitória, Brasil

mauricio.s.oliveira@ufes.br ○ https://orcid.org/0000-0002-4779-0092

Anna Stella Silva de Souza

Mestra

Núcleo de Pesquisa em Ginástica (NPG),

Universidade Federal do Espírito Santo,

Vitória, Brasil

annastella.souza@gmail.com

D https://orcid.org/0000-0002-2785-9179

Myrian Nunomura

Doutora

Escola de Educação Física e Esporte de Ribeirão Preto, Universidade de São Paulo,

Ribeirão Preto, Brasil mnunomur@usp.br

https://orcid.org/0000-0002-3669-0571 


\begin{abstract}
Permeated by the ideological system of gender, which influenced the roles and values that dictated what women could and could not do in society and in sport, female gymnasts began to compete in Artistic Gymnastics (AG) in the early decades of the 20th century. The aim of this study was to shed light on the consolidation of official apparatus in the competitive format of women's AG through the analysis of uneven parallel bars, an apparatus initially adapted from the male discipline. It is perceived that, over time, women were subjugated to the medical and social discourse that dictated the use of their bodies at the core of this sport and in society. But through small steps and the development imposed by the athletes themselves, there was a need to build their own apparatus that symbolically reveals that women wanted to direct women's AG on their own terms.
\end{abstract}

KEYWORDS: Gymnastics apparatus; Women in sports; Olympic games

Marcando espacio para mujeres en gimnasia artística con magnésio: la consolidación de las barras paralelas asimétricas entre los años 1952-1964

\title{
RESUMEN
}

Las gimnastas empezaron a competir en GA en las primeras décadas del siglo XX, cuando el sistema ideológico de género dictaba lo que ellaspodían y no podían hacer en la sociedad y en el deporte. El objetivo de este estudio fue lanzar luz sobre la consolidación de los aparatos oficiales en el formato competitivo de GA femenina a través del análisis de las barras paralelas asimétricas, aparato inicialmente adaptado de la disciplina masculina. Se percibe que, con el tiempo, las mujeres fueron sometidas al discurso médico y social que dictaba el uso de su cuerpo en este deporte y en la sociedad. Pero a través de pequeños pasos y el desarrollo impuesto por las propias atletas, surgió la necesidad de construir su propio aparato que revelara simbólicamente que las mujeres querían dictar las direcciones de la GA femenina en sus propios términos.

PALABRAS-CLAVE: Aparatos de gimnasia; Mujeres en el deporte; Juegos olímpicos 


\section{INTRODUÇÃO}

A história das mulheres no esporte é uma história pessoal, porque nada é mais pessoal do que os ossos, os tendões, o suor e o desejo de uma mulher, é uma história política, porque nada é mais poderoso do que a luta de uma mulher para se libertar. É a história da liberalização das mulheres - não apenas para aquelas que vieram antes, mas para aquelas de nós que estão aqui agora, se alongando, se esforçando e se perguntando: o que posso alcançar? $\mathrm{O}$ que as mulheres podem alcançar juntas? (NELSON, 1998).

Pfister (1999) reflete que a maioria das sociedades tem sido e ainda é dominada pelos homens. Nesse contexto, os homens tendem a assumir o protagonismo na cultura corporal e do movimento. No entanto, segundo a autora e Nelson (1998), supracitada, percebemos que no decorrer do tempo as mulheres conseguiram desenvolver e praticar sua própria cultura corporal de movimento, inclusive, com sucesso de participar dos esportes ditos masculinos.

Com a inserção das mulheres nas práticas esportivas e nas competições, como os Jogos Olímpicos, o esporte se tornou um cenário de conflitos e de lutas sobre o que uma mulher poderia ser e fazer nesse âmbito. Os embates estavam relacionados ao acesso dos espaços, à legitimidade e aos recursos materiais e, também, aspectos simbólicos que representavam uma luta pelo controle sobre o seu próprio corpo e da sua vida (ADELMAN, 2006).

O esporte tem sido visto como um espaço de domínio masculino, ou seja, monopolizado pelos homens e, também, por sua masculinidade (BRANDÃO; CASAL, 2003). Observamos que o controle ideológico exercido pelos homens sobre o esporte estabeleceu padrões que, conforme Morais (2004), impõe uma ideia estigmatizada de que os homens atletas são mais fortes e competitivos quando comparados às mulheres atletas. Isso estaria vinculado tanto aos fatores biológicos e psicológicos, como de ordem social.

Ao percorrermos a história da mulher no esporte, mais precisamente até a década de 1950, observamos que não era recomendado tanto correr como praticar atividades esportivas e competir (ALONSO, 2003). Ainda de acordo com Alonso (2003), era hegemônico o pensamento de que os esportes e as suas consequências, como melhorar a definição muscular, aumentar a capacidade pulmonar e diminuir a gordura corporal, afastariam a mulher de seu destino "natural" que preconizava o casamento e a maternidade. Devide (2005), fundamentado em Willis (1994), complementa que "ser bem sucedida como atleta pode significar falhar como mulher, quando não se pode contemplar os papéis socialmente designados para elas" (p. 42). Assim, segundo Pfister (2000), tanto a educação física quanto o treinamento para as mulheres deveriam prepará-las para seus futuros papéis como mães e "cidadãs de valor". 
Inseridas nesse contexto supracitado, Huguenin (1981) afirma que o advento das mulheres na prática da Ginástica Artística (GA) ocorreu a passos pequenos, pouco a pouco, o qual se iniciou com as apresentações sem caráter competitivo em festivais no final do século XIX. Ainda que houvesse resistência dos homens, as mulheres praticavam a ginástica nas sociedades gímnicas e, assim, foram encontrando o seu próprio caminho no cerne dessa manifestação corporal. Salientamos que quando foi inaugurado o primeiro parque ginástico em 1811 em Hasenheide, Berlim, considerado o berço da GA (PUBLIO, 2002), as mulheres não puderam participar da ginástica preconizada por Friedrich Ludwig Jahn (PFISTER, 2004).

Nesse período inicial, competia às mulheres apenas o papel de espectadoras, pois a ênfase na preparação militar e os objetivos patrióticos as afastaram do programa de ginástica elaborado por Jahn. "Além disso, escalar postes e balançar em cordas eram atividades "impróprias” para o "sexo fraco"” (PFISTER, 1999, p. 444). Assim, no decorrer do Século XIX, as mulheres foram inseridas nesse viés estigmatizado em uma ginástica que privilegiava exercícios que não sacrificavam a feminilidade e que visavam sempre à preservação da decência:

os professores geralmente tomavam o cuidado de limitar os movimentos de suas alunas a exercícios disciplinares, os quais instituíam obediência. Para preservar a "decência", as garotas alemãs, por exemplo, não tinham permissão para realizar exercícios que exigiam que elas afastassem as pernas ou as levantassem acima da cintura (PFISTER, 1999, p. 445).

Por volta de 1850, o número de sociedades gímnicas que ofereciam a prática da ginástica para mulheres aumentou e, conforme Huguenin (1981), esse movimento continuou a crescer até o final do Século XIX. Segundo o autor, esse aumento foi catalisado por meio dos festivais que auxiliaram a disseminação da prática de ginástica entre o público feminino. Ademais, podemos incluir educadores que promoveram a ginástica para as mulheres e contribuíram com a participação feminina, como exemplos: Phokion Heinrich Clias, Adolf Spiess e Johann Adolf Ludwig Werner (HAGELIN,1995).

Huguenin (1981) destaca que o movimento dos Sokols, nas antigas Tchecoslováquia e Iugoslávia, também impulsionou essa participação feminina na ginástica. Ressaltamos que essa organização de ginástica foi fundada no ano de 1862, a qual foi responsável por transformar o sentimento de nacionalismo em um movimento de massa em busca de liberdade (NOLTE, 2002). Bábela e Oborný (2018) e Kabes (2003) citam que MiroslavTyrš, fundador desse movimento, acreditava que uma nação não era composta apenas por seus homens, e que as mulheres tinham a responsabilidade de educar as crianças, além de que a maternidade permitia implantar as melhores qualidades. Destarte, Kabes (2003) refere que Tyrš iniciou e ajudou a estabelecer, no ano de 1869, a 
Sociedade Ginástica de Mulheres e Meninas de Praga, a qual pode ser compreendida como o berço do Sokol para as mulheres.

Conforme Kabes (2003), o Sokol tcheco se expandiu nas regiões da Boêmia e da Morávia, assim como para outros países: Eslovênia, Sérvia, Polônia e Croácia. Isso inspirou a organização dos grandes festivais de massa, denominados Slets, que buscavam reunir os grupos que compunham o movimento. Esses aspectos relativos ao Sokol nos auxiliam a compreender o posicionamento de Huguenin (1981) acerca da importância dessa organização na ginástica para mulheres, seja por meio da célula máter na Sociedade Ginástica de Mulheres e Meninas ou pela organização dos festivais.

Compete mencionar que, um marco no movimento das mulheres nos primórdios da GA no início do Século XX, ocorreu com a realização do primeiro festival internacional com a atuação feminina, mais precisamente em Luxemburgo, em 1909. E, no ano de 1913, ocorreu a primeira competição em Leipzig na Alemanha (HUGUENIN, 1981). Esses fatos históricos reforçam a importância dos eventos no desenvolvimento de uma ginástica para as mulheres.

A obra comemorativa dos 100 anos da Federação Internacional de Ginástica (FIG) destaca o ano de 1928 como um momento decisivo para a categoria feminina de GA, pois naquele ano foi realizada a primeira competição internacional para mulheres nos Jogos Olímpicos de Amsterdam (HUGHENIN, 1981). Nesse marco para a modalidade, as mulheres competiram apenas por equipes. Goehler (1978) reflete que "apresentar uma competição individual seria ousado demais para a época" (p. 16).

Esse pensamento de Goehler, que considerava prudente manter a competição apenas por equipes, pode ser compreendido por meio da análise de discursos daquele período histórico e que foram expostos por Guttmann (1991, p. 139-140):

Frederick R. Rogers compartilhou as convicções da Divisão Feminina e compartilhou-as em um artigo da SchoolandSociety de 1929 intitulado "Olimpíadas para garotas?" Explicando que "os homens são mais semelhantes aos animais, móveis, enérgicos, conscientes, enquanto as mulheres são mais semelhantes às plantas, mais presas ao solo", Rogers respondeu à sua própria pergunta retórica com uma negativa retumbante: "Formas intensas de conflitos físicos e psíquicos... tendem a destruir o encanto físico e psíquico das garotas e a adaptabilidade para a maternidade". Escrevendo na Scientific American, Donald A. Laird dispensou a imaginação animal-vegetal, mas chegou à mesma conclusão não científica. Embora a pesquisa médica tenha demonstrado claramente o contrário, ele anunciou que "o desenvolvimento muscular feminino interfere na maternidade".

Observamos no excerto os desafios que as mulheres enfrentaram para lograr o seu espaço no esporte e, no caso do nosso estudo, na GA. Principalmente, tendo em vista que se tratava de um universo dominado pelo sexo masculino com o apoio dos estereótipos de gênero vigentes na 
sociedade. Talvez, por isso, o número de equipes na primeira competição internacional foi pequeno. Huguenin (1981) cita que 5 equipes participaram da disputa, cujo programa contemplava exercícios em grupo, com e sem aparelhos manuais, um salto e um exercício opcional sobre aparelhos. "Esse evento foi o ponto de partida para as competições internacionais que, pouco a pouco, estavam sendo organizadas na Europa" (HUGUENIN, 1981, p. 103).

No ano de 1933 , no $20^{\circ}$ Congresso da FIG, foi constituído um Comitê Técnico para zelar pela categoria feminina da GA. Segundo Huguenin (1981), a partir desse momento "a liderança e a avaliação dos eventos foi entregue às mulheres e, desde então, a GA feminina é liderada por uma comissão independente, cuja primeira presidente foi a senhora Zamoyska" (p. 106).

Após a criação do Comitê Técnico, as mulheres participaram do seu primeiro Campeonato Mundial em 1934, na cidade de Budapeste. Elas competiram nesse evento cujo programa abarcava provas de atletismo (salto em distância, arremesso de dardos e corrida de 60 metros) e de ginástica (exercícios livres por equipes, exercícios por equipes com aparelhos manuais, salto sobre o cavalo, trave de equilíbrio de $8 \mathrm{~cm}$ e barras paralelas simétricas). Segundo Huguenin (1981), pela primeira vez mulheres atuaram na arbitragem.

Nos Campeonatos Mundiais subsequentes, 1938 e 1950, bem como nas edições de 1936 e 1948 dos JO, as mulheres continuaram restritas às disputas por equipes. Ressaltamos que nos JO de Londres as ginastas competiram em exercícios obrigatórios nas argolas, aparelho da GA masculina na atualidade (THE ORGANISING COMMITTEE FOR THE XIV OLYMPIAD, 1948).

Huguenin (1981) expõe que no ano de 1950 a ginástica estava no alvorecer de sua era contemporânea. Essa perspectiva pode ser compreendida pelas mudanças propostas no $28^{\circ}$ Congresso da FIG realizado em Estocolmo em 1949. Na ocasião, foi decidido o formato competitivo que restringiu os aparelhos em seis no masculino e quatro no feminino, os quais continuam em vigor até o momento atual, ou seja, as provas de atletismo estavam excluídas do programa da modalidade.

No caso específico das mulheres, as ginastas ficaram restritas ao salto sobre o cavalo na transversal, as barras paralelas assimétricas, a trave de equilíbrio e o solo que, conforme Aykroyd (1985), eram aparelhos mais adequados à feminilidade das mulheres quando comparadas aos masculinos que exigiam força.

É pertinente mencionar que essas mudanças não foram efetivadas no mundial de 1950 e só entraram em vigor nos Jogos Olímpicos de 1952 e no campeonato mundial seguinte realizado em 1954. Ademais, a entrada nessa nova era também foi motivada pelo lançamento do primeiro Código de Pontuação masculino em 1949, que foi um marco na GA como um todo (OLIVEIRA; BORTOLETO, 2009). 
A efetivação do formato competitivo nos quatro aparelhos possibilitou a normatização da GA para mulheres, a qual foi ratificada com o advento do primeiro Código de Pontuação feminino em 1954. Tendo em vista esse momento importante para os direcionamentos do desenvolvimento da GA feminina, assim como o enfrentamento das mulheres para se inserirem nas competições esportivas, o objetivo desse estudo foi percorrer o período de 1952 até 1964 sobre os desdobramentos do estabelecimento dos aparelhos da categoria feminina. Como recorte metodológico, elegemos por analisar a inserção das barras paralelas assimétricas, a qual foi um símbolo de compartilhamento e de desmembramento entre as duas categorias. Trata-se de um aparelho que teve a sua gênese na prática da ginástica estritamente para homens.

Para o desenvolvimento do estudo, optamos por contextualizar o percurso histórico desse artefato cultural da modalidade por meio de uma pesquisa histórica, desde a sua origem no cerne do Método Alemão até o período analisado no estudo. Ademais, elencamos as protagonistas da modalidade entre os anos de 1952 e 1964, que direcionaram os rumos da modalidade.

Salientamos que a FIG considera o período de 1952 até 1964 como a era da GA estritamente esportiva e que marcou a entrada da modalidade na era contemporânea (HUGUENIN, 1981). Assim, pressupomos que se trata de um período que balizou a busca da identidade das mulheres nesse esporte, tendo em vista os embates sociais que permeavam a participação dessas desde a origem da modalidade.

\section{PERCURSO METODOLÓGICO}

Trata-se de uma pesquisa histórica, a qual foi orientada à produção de novos conhecimentos por meio da elaboração de novas formas de compreender certos fenômenos do passado, bem como lançar luz sobre novas perspectivas de como esses fenômenos têm-se desenvolvido (RICHARDSON, 1999).

Nas palavras de Isaac e Michael (1981, p. 44), a pesquisa histórica tem o propósito de "reconstruir o passado de forma sistemática e objetiva coletando, avaliando, verificando e sintetizando evidências para estabelecer fatos e chegar a conclusões defensáveis, muitas vezes em relação a hipóteses específicas". Há preocupação em compreender o passado na busca pela extração de princípios gerais que possam orientar a sociedade no presente e no futuro (GRESSLER, 2003).

Nesse sentido, esse método de estudo nos permite interpretar em profundidade e em seus detalhes as estruturas sociais existentes, as quais não devem ser restritas e pensadas conforme o critério de normas ou regras vigentes na sociedade atual, mas como resultados de decisões que 
ocorreram no passado. Gressler (2003) alude que a pesquisa histórica "contribui para o conhecimento do presente à luz dos acontecimentos passados” (p. 50). Assim, torna-se possível compreender certas causas ou tendências atuais por meio de acontecimentos passados que são capazes de ajudar no esclarecimento de fatos no presente, além de permitir antecipar efeitos no futuro.

Corroboramos Matejski (1986) que a pesquisa histórica é descritiva, factual e fluída. E, inseridos nessa compreensão de fluidez, essa abordagem de pesquisa vai além da mera coleta de dados sobre incidentes, fatos, datas e imagens. Pois, segundo Glass (1989), ao analisar a reflexão de Notter (1972), a pesquisa histórica prima o relacionamento de aspectos que influenciaram o passado, continua a influenciar o presente e, possivelmente, afetarão o futuro.

Para a coleta de dados, recorremos à pesquisa documental. De acordo com Godoy (1995), essa abordagem pode ser constituída por documentos primários e secundários.

A diferença fundamental entre fonte primária e secundária consiste em que as fontes primárias são constituídas de textos originais, com informações de primeira mão; as fontes secundárias constituem-se da literatura a respeito de fontes primárias, isto é, de obras que interpretam e analisam fontes primárias (ANDRADE, 2018, p. 29).

Em outras palavras, a pesquisa documental, ou de fontes primárias, englobam as obras que ainda não foram analisadas ou interpretadas (ANDRADE, 2018). No caso do nosso estudo, nessa etapa consultamos as diretrizes e os relatórios de cada edição dos Jogos Olímpicos que estão disponíveis na Biblioteca Mundial Olímpica e, também, na Fundação LA84. Ademais, examinamos as revistas pioneiras no campo da ginástica, as quais: Mademoiselle Gymnast, ModernGymnast e InternationalGymnast.

Ademais, recorremos à pesquisa bibliográfica, também denominada de fonte secundária (GODOY, 1995), na qual selecionamos, fichamos e arquivamos tópicos que seriam de interesse da pesquisa e que foram publicados, como: documentos impressos, artigos científicos, livros, teses e dissertações.

\section{FLERTANDO COM A FORÇA E A OUSADIA EM EXIBIÇÕES DE GRAÇA E LEVEZA ENTRE AS BARRAS}

Mattern (1996) esclarece que as barras paralelas assimétricas consistem em um aparelho que foi aperfeiçoado das barras paralelas masculinas, especificamente, para o uso das mulheres. De 
acordo com o autor, o objetivo da adaptação das paralelas simétricas era suprir as limitações físicas do corpo feminino.

Embora seja de conhecimento geral, no percurso histórico desse aparelho observamos outras finalidades. Por isso, para compreendermos melhor a história das paralelas assimétricas no período de consolidação da GA feminina, torna-se necessário voltarmos no tempo a partir do período do Método Ginástico alemão. Pois, foi no interior dessa escola ginástica que as primeiras barras paralelas foram criadas por Jahn, mais especificamente, na década de 1810 com a premissa de ser um aparelho auxiliar nos exercícios de preparação física para o cavalo (KAIMAKAMIS et al., 2010; HERHOLZ, 2020).

De acordo com Prestidge (1979), Jahn notou que os homens não possuíam força suficiente nos braços para realizar os exercícios específicos no cavalo. Com isso, o pai da GA construiu um equipamento de treinamento simples, o qual era constituído por duas barras que foram colocadas na mesma largura das alças do cavalo, porém mais altas. "Então, segurando as barras uma em cada mão, eles se erguiam para cima e para baixo, injetando força e potência nos braços e ombros" (PRESTIDGE, 1979, p. 39).

As primeiras paralelas foram construídas a partir de dois barrotes de madeira que foram pregados em troncos de árvores e, posteriormente, passaram a ser fixados em quatro postes firmados no solo (KAIMAKAMIS et al., 2010). Herholz (2020) fornece novos subsídios que complementam Kaimakamiset al. (2010), pois o autor esclarece que os barrotes estavam fixados em troncos de madeira cujas bases ficavam enterradas, aproximadamente, $30 \mathrm{~cm}$ para proporcionar estabilidade.

Publio (2002) cita que na obra A TreatiseonGymnastics, de 1828, Jahn descreveu que o aparelho era constituído por dois barrotes paralelos, confeccionados em madeira, que possuíam o comprimento de 8 pés e ficavam dispostos sobre dois postes de sustentação.

Cada barra tem 3 polegadas de espessura e 2 1/2 polegadas de largura, são arredondadas e sem extremidades pontiagudas. Os postes podem ser mais grossos, mas devem ser reduzidos, na direção das barras. Os postes também não devem ter extremidades pontiagudas. Devem ser inseridos a um pé de distância do final da barra. As barras paralelas não podem ser mais altas que as axilas para iniciantes, podendo, para os mais experientes, ser acima da altura da cabeça (PUBLIO, 2002, p. 305).

Alguns anos depois, em 1830, Francisco Amoros escreveu sobre as barras paralelas assimétricas no seu livro Manuel d'EducationPhysiqueetMorale (HERHOLZ, 2020). Apesar desse pioneirismo no trato das paralelas com barrotes em diferentes alturas, é importante salientar que 
essa adaptação não estava relacionada às mulheres, pois as circunstâncias sociais da época restringiam a participação feminina, a qual estava longe de ser igualitária. Para as mulheres, por volta desse período, restou o uso desse aparelho simétrico para o tratamento e a reabilitação de deficiências posturais (KAIMAKAMIS et al., 2010), como podemos observar na Figura 1 da obra deGuillaumeJalade-Lafond de 1829.

Figura 1 - Exercícios ginásticos terapêuticos propostos por GuillaumeJalade-Lafond.

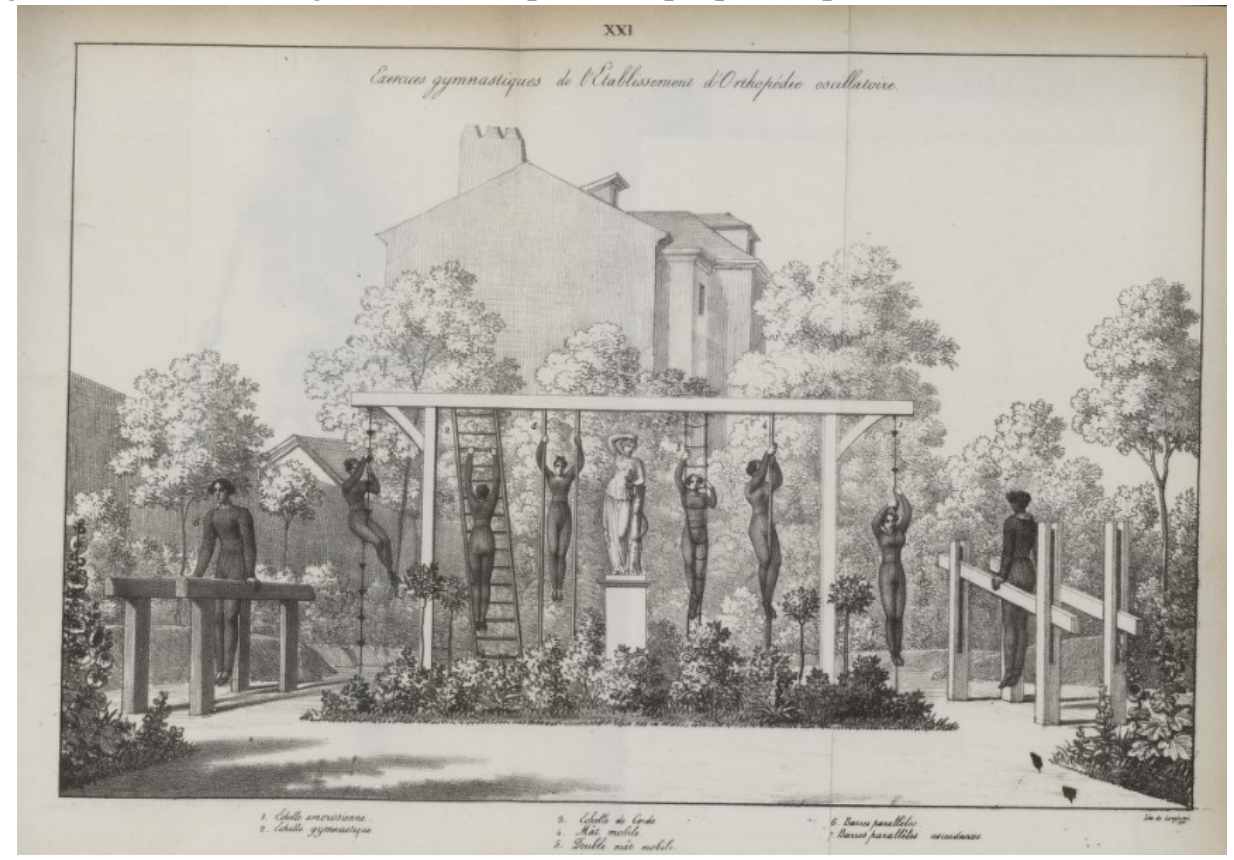

Fonte: Jalade-Lafond(1829).

Já no século XX, com o advento de competições para mulheres, Herholz (2020) cita os exercícios obrigatórios nas barras paralelas simétricas no ano de 1927 no contexto alemão. E, no ano seguinte, o Comitê Executivo dos Jogos Olímpicos de Amsterdam também indicou a possibilidade das mulheres utilizarem esse aparelho na competição por equipes (EXECUTIVE COMMITTEE AMSTERDAM, 1928).

Torna-se pertinente mencionar que, no princípio, segundo Tonry e Tonry (1980) e Sands e Conklin (1984), o aparelho era o mesmo para homens e mulheres, sendo que o público feminino competia com ajustes na largura e na altura do aparelho para acomodar seus corpos. Conforme descrito por Sands e Conklin (1984), nesse período as mulheres tinham dificuldades de se balançar entre os barrotes devido à falta de força nos membros superiores. E, quando a distância das barras era diminuída, havia a barreira dos quadris largos que eram valorizados na época como padrão de beleza e vinculados ao papel da mulher na maternidade. 
Compete mencionar que os exercícios das mulheres nesse aparelho eram baseados em habilidades de apoio duplo, exemplo, braços e pernas apoiados ao mesmo tempo nas barras (TONRY; TONRY, 1980). Mas, "as melhores mulheres orgulhavam-se de dominar as habilidades masculinas mais extenuantes" (TONRY; TONRY, 1980, p. 157).

Para atender aos anseios sociais e médicos da época, no primeiro campeonato mundial com a participação feminina, em 1934, as barras com os barrotes assimétricos foram inseridas no programa feminino pela primeira vez (HERHOLZ, 2020), o intuito era suprir as limitações físicas das mulheres. É importante destacar que a ideia de utilizar as paralelas, com os barrotes em alturas distintas, no contexto de apresentações, antecedeu o cenário competitivo e foi observada no movimento Sokol. Palka e Siwek (2018), ao narrarem a história do segundo festival do Sokol polonês na cidade de Lvov, em 1894, citam exercícios realizados em paralelas assimétricas, mas com a participação restrita masculina.

Fatores distintos suscitaram a transição das paralelas simétricas para as assimétricas, dentre os quais: a força necessária para executar os movimentos nas paralelas simétricas (CARVALHO, 2004); e a possibilidade das mulheres criarem séries com o foco maior na graça e na flexibilidade em detrimento da força (GUTMAN, 1996). É perceptível a influência do viés científico daquele período sobre o corpo da mulher, pois se acreditava que a força, a velocidade e a resistência não eram capacidades físicas apropriadas para o sexo feminino (OLIVEIRA; POLIDORO; SIMÕES, 2003).

Nos Jogos Olímpicos de 1936, as mulheres competiram nas paralelas assimétricas nos exercícios obrigatórios e tinham a opção de escolher o aparelho com os barrotes simétricos na competição livre. Porter (2004) destaca que apenas a equipe da antiga Tchecoslováquia optou pelas barras assimétricas. Publio (2002) analisa que as orientações da FIG na época direcionavam as séries nas barras paralelas assimétricas para "muitas poses e movimentos estáticos" (p. 307), fato perceptível na descrição dos exercícios obrigatórios dessa edição olímpica (ORGANISATIONSKOMITEE FÜR DIE XI. OLYMPIADE BERLIN 1936, 1937).

No programa olímpico de 1948, com o retorno dos Jogos Olímpicos após a Segunda Grande Guerra, as barras paralelas não foram inseridas na competição das mulheres (THE ORGANISING COMMITTEE FOR THE XIV OLYMPIAD LONDON, 1948). E, "no Campeonato Mundial de 1950 em Basel, as barras assimétricas ainda não eram totalmente aceitas, pois as mulheres podiam (pela última vez) escolher entre as barras assimétricas e as argolas de balanço" (HERHOLZ, 2020).

A consolidação do uso dos barrotes assimétricos ocorreu em 1952, nos Jogos Olímpicos de Helsinki, quando as mulheres competiram nesse aparelho nos exercícios compulsórios e livres (ORGANISING COMMITTEE FOR THE XVTH OLYMPIC GAMES HELSINKI 1952, 1952). 
Segundo o comitê organizador, elementos de suspensão e de impulso deveriam prevalecer durante a série. E, a recomendação era de que movimentos no apoio deveriam ser momentâneos. Acerca dos equilíbrios, esses elementos poderiam ser realizados desde que conectados às barras, as quais estavam dispostas na altura de 2,30 m e 1,50 m com uma distância entre elas que poderia variar entre 42-46 cm. O comprimento do barrote era 3,50 m e no formato oval.

A primeira campeã olímpica de paralelas assimétricas foi a húngara MargitKorondi. Phillips (1957) cita que a ginasta iniciou a prática da modalidade aos três anos de idade. Mas, conforme o jornal Szabadság (2020), apenas em 1946 iniciou o treinamento regular com o fim da II Guerra Mundial. Na sua primeira aparição olímpica, Korondi era a ginasta mais nova da equipe com 20 anos de idade e, por meio de seus movimentos impecáveis, ultrapassou os limites para vencer a disputa (SABADSÁG, 2020).

Dois anos depois da competição olímpica em Helsinki, mais precisamente no mundial de 1954, Herholz (2020) pontua que as mulheres continuavam a competir nas barras paralelas masculinas adaptadas com os barrotes assimétricos. Mas, o desenvolvimento feminino já demonstrava a necessidade de um aparelho próprio com maior estabilidade e barrotes adequados. $\mathrm{O}$ autor cita que 39 barrotes foram quebrados ao longo daquela competição.

Tanto no mundial de 1954 quanto nos Jogos Olímpicos de 1956, já eram utilizados estabilizadores nos postes de sustentação do barrote alto, o qual proporcionava maior firmeza ao aparelho. Isso denota a preocupação com a segurança das atletas ao longo dos exercícios. O uso dos estabilizadores foi um avanço para legitimar as mulheres nessa prova, tendo a premissa de que se tratava de um aparelho que emergiu e direcionou as mulheres segundo pressupostos da ginástica masculina, mas, nesse momento, elas buscaram novos elementos que o aparelho dos homens adaptado não comportava.

Em 1956, a vencedora da prova olímpica foi a húngara Agnes Keleti, a qual teve sua história marcada pela repressão nazista. Leavy (1998) cita que Keleti era uma ginasta promissora quando os Jogos Olímpicos de 1940 foram cancelados por causa da guerra. E, as consequências da expansão nazista, por meio da ocupação da Hungria, impactaram na vida da jovem atleta judia que foi expulsa do clube onde praticava GA. Agnes Keleti sobreviveu ao período difícil de repressão nazista, mas seu pai foi assassinado na câmara de gás. Com o fim da II Guerra Mundial, a ginasta voltou aos treinos com 27 anos. Melbourne foi a sua segunda edição dos Jogos Olímpicos, tendo participado com sucesso na edição anterior. Aos 35 anos de idade, Keleti se tornou campeã de barras assimétricas e até hoje se mantém como a ginasta medalhista de ouro mais velha na GA (LEAVY, 1998). 
Após Melbourne, observamos mudanças na estrutura do aparelho, mais especificamente, no poste do barrote alto. O Comitê Organizador dos Jogos Olímpicos de Roma (COMITATO ORGANIZZATORE DEI GIOCHI DELLA XVII OLIMPIADE, 1960) detalhou nas especificações desse aparelho a necessidade de uma base pesada para oferecer o máximo de estabilidade e, além disso, consolidou o uso dos estabilizadores: "para garantir sua estabilidade absoluta, será previsto um suporte transversal, fixado por um lado na parte superior do poste e, por outro lado, à base” (p. 28). Tratavam-se de mudanças necessárias, pois, conforme Takemoto e Hamada (1958), as mulheres seguiam uma tendência de distanciamento dos movimentos das barras simétricas para se aproximar daqueles realizados na barra fixa masculina, o qual era restrito apenas aos homens.

Essas mudanças sinalizavam que as mulheres necessitavam cada vez mais de um aparelho próprio e que estivesse aliado aos movimentos desenvolvidos por elas. Compete dizer que, no aparelho utilizado em Roma, apenas o barrote baixo permitia estreitar ou aumentar a distância entre as barras que variava entre 43-48 cm (COMITATO ORGANIZZATORE DEI GIOCHI DELLA XVII OLIMPIADE, 1960). As outras medidas do aparelho eram: barra superior disposta na altura de $230 \mathrm{~cm}$ com a barra inferior elevada à $150 \mathrm{~cm}$. O comprimento do barrote era $350 \mathrm{~cm}$ com a dimensão de 41 x $51 \mathrm{~mm}$, o qual era confeccionado em madeira no formato oval.

A grande estrela da competição nesse aparelho foi a ucraniana PolinaAstakhova da União Soviética que começou a prática da modalidade com a idade de 13 anos e que logrou a medalha de ouro aos 23 anos. Simonov (1961), ao referenciar Polina, enalteceu a sua habilidade e graciosidade nos aparelhos. E, ao analisar o desempenho da atleta nas barras cita que:

a alta e loira Polina girava em uma sequência de movimentos deslumbrantes nas barras. A multidão assistia fascinada. Então, alguém na arena gritou: "é uma sinfonia de graça". Isso quebrou o silêncio e houve uma explosão de aplausos tumultuados (p. 64).

Goodbody (1982), ao retratar a série de Polina Astakhova, expõe que a ginasta "graciosa e aparentemente frágil, atraiu a atenção com sua charmosa rotina de barras assimétricas". A forma como Simonov (1961) e Goodbody (1982) abordaram a conquista da medalha de ouro por Polina Astakhova evidencia o estereótipo feminino de fragilidade e de graciosidade, os quais eram atributos permitidos e recomendados no universo das mulheres atletas. Embora a série da atleta exibisse resistência, velocidade e potência, essas características estavam associadas à masculinidade e não foram retratadas pelos autores ao relatar a conquista da atleta. Polina Astakhova se consagraria bicampeã olímpica em 1964. E, ao analisarmos o aparelho após quatro anos, verificamos que nos aspectos morfológicos não houve mudanças (COMITE D'ORGANISATION 
DES JEUX DE LA XVIII OLYMPIADE, 1963), mas havia uma progressão da variedade e da dificuldade dos elementos.

Gutman (1996) esclarece que nos anos 1960 era permitido que as ginastas fizessem duas pausas durante a realização das séries, ou seja, havia a possibilidade de descansar os membros superiores ao permanecer no apoio dos pés ou de outras partes do corpo. Esse zelo era influenciado pelos valores vigentes na sociedade, que incidiam na participação das mulheres no esporte em geral. Corroboramos Guttmann (1991) quando o autor reflete que nas entrelinhas da ênfase na graça presente na modalidade, também havia o componente da força. Uma força que era necessária para que os movimentos parecessem graciosos mesmo que a demanda física estivesse além daquele que muitos homens poderiam suportar.

Simões (2003) cita a dicotomia de homem/forte e mulher/fraca que, na concepção do autor, funcionou como uma "lei da natureza" que delineava as expectativas atribuídas às mulheres nos diferentes segmentos sociais. Ademais, havia a preocupação por corpos femininos socialmente aceitáveis e úteis, os quais eram resultados do processo de formação e de adestramento que se iniciavam na infância e que eram constantemente enfatizados ao logo da vida dos indivíduos. Então, durante esse processo de socialização humana, até a década de 1970, o corpo feminino tinha que seguir uma forma do que era considerado normal e saudável (ALONSO, 2003), uma vez que o normal era ter uma estrutura óssea que auxiliasse no parto.

Portanto, quadris largos eram apreciados, enquanto braços com bíceps torneados não eram tão recomendados, visto que a demonstração de força poderia afastar os possíveis pretendentes para o matrimônio (ALONSO, 2003). Pfister (2004) menciona que até a década de 1970, as ginastas eram descritas como sendo de altura média, esbeltas, flexíveis e graciosas. Uma graciosidade com finalidade utilitária na sociedade, pois, conforme Alonso (2003), ela era necessária para conquistar um marido com o fim de torná-lo o pai de seus filhos.

Nesse sentido, observamos que as barras assimétricas tiveram a finalidade de fazer uma oposição às barras paralelas masculinas e às suas características que requisitavam valências físicas do universo masculino, pois o raciocínio era de que as mulheres não tinham a força necessária para atuar nas barras simétricas, além de que a mudança permitiria uma maior variedade na expressão artística (KERR, 2003). Frederick (1962) reflete com os leitores da revista The ModernGymnast que a motivação para as meninas e as mulheres terem adotado as barras assimétricas foi a falta de força para permanecer no apoio dos membros superiores: "As mulheres não têm a força necessária para se desenvolver naturalmente no trabalho com as barras simétricas" (p. 25). Além disso, o autor menciona as escoriações doloridas ocasionadas pelo apoio branquial. 
Apesar da oposição ao aparelho com barrotes simétricos, citada por Kerr (2003), observamos que o aparelho assimétrico continuou sob a influência de uma ideologia patriarcal que buscava justificar uma superioridade masculina na sociedade e no esporte ao julgar a feminilidade. Isso é evidenciado pela forma como as atletas eram relatadas na mídia e, também, pelo viés biológico que justificava as ações motoras propícias desse aparelho e as capacidades físicas indicadas para serem desenvolvidas pelas mulheres. Isso sempre com a premissa de que as alterações no corpo e na natureza feminina traziam o risco da masculinização.

\section{CONSIDERAÇÕES FINAIS}

Ao refletirmos sobre o movimento das mulheres no âmbito esportivo e, no caso específico desse estudo, na GA, observamos que consistiu em uma jornada desafiante contra a hegemonia de estereótipos e valores impostos pela sociedade. A marcha das mulheres atletas representou a busca por um tratamento igualitário e o direito de controlar seus próprios corpos. Trata-se de uma jornada marcada pela autodeterminação e a busca pelo reconhecimento das suas capacidades dentro e fora do âmbito esportivo, uma batalha que ainda não findou.

$\mathrm{Na}$ história da mulher no esporte, Oliveira, Polidoro e Simões (2003) alertam que o ideal de supremacia masculina declarava que a prática de exercícios intensos prejudicaria a saúde das mulheres e, assim, impedi-las de participar seria uma medida preventiva e não discriminatória. Por isso, inseridas nesse contexto, as ginastas galgaram o seu próprio espaço na GA a passos pequenos e envoltos por obstáculos culturais.

Refletimos que as mulheres lutaram e conquistaram o acesso ao âmbito competitivo da modalidade, mas os homens continuaram a resistir e imprimir o que as atletas poderiam ou não fazer no esporte. Havia a preocupação de despi-las de suas qualidades femininas caso fossem na direção do esporte considerado do universo dos homens, pois se alegava que isso pudesse masculinizá-las (SIMÕES; CONCEIÇÃO; NERY, 2004).

Nesse sentido, observamos que as mulheres ginastas travaram uma disputa que não se restringiu apenas ao direito de praticar a modalidade, mas, também, ao domínio do seu próprio corpo. Trata-se de uma luta que teve início ainda no século XIX no arcabouço da primeira onda do feminismo (SILVA, 2018), a qual ficou marcada principalmente pelo "sufragismo", luta pelo direito ao voto (LOURO, 1997). Mas, após um momento de acomodação do movimento feminista, as questões relativas ao corpo da mulher ganharam força na segunda onda que teve o início de seu 
lapso temporal na década de 1960. Segundo Almeida (2020), o feminismo desse período trouxe visibilidade para a opressão sofrida pela mulher ocasionada pelo sistema patriarcal que subjugava as mulheres à esfera privada, à realização de tarefas domésticas e à reprodução. A autora alerta que a segunda onda trouxe o debate público acerca do corpo da mulher, sendo marcada pela luta pelo direito ao corpo.

$\mathrm{Na}$ GA, a articulação para as mudanças começou com o advento de um Comitê Técnico Feminino na década de 1930, mesmo período em que as barras paralelas assimétricas foram inseridas no programa olímpico de 1936. No entanto, a consolidação desse aparelho na GA feminina, só viria a ocorrer em 1952 quando foram definidos os quatro aparelhos que são utilizados até os dias de hoje.

Apesar da conquista desse formato competitivo, as mulheres continuaram a competir no aparelho masculino que era apenas adaptado com os barrotes em alturas distintas nos anos seguintes. Ademais, as ginastas carregavam consigo o estereótipo do feminino que, conforme Simões, Conceição e Nery (2004), trazia "conotações negativas, como fragilidade, meiguice, vaidade e timidez" (p. 64), ou seja, a exibição de elementos de força contrariaria essa visão de mulher hegemônica e aceita na sociedade.

No entanto, as tradições machistas, que sempre limitaram o envolvimento das mulheres nos diversos esportes, não foram capazes de impedir suas ações na modalidade, pois as normas e os preconceitos foram e continuam a ser derrubados por inúmeras atletas (SIMÕES, 2003). Assim, o desenvolvimento das mulheres nas barras assimétricas impulsionou a necessidade de um aparelho propício para a GA feminina, pois os movimentos se distanciaram das paralelas simétricas na direção daqueles observados na barra fixa, um aparelho restrito aos homens. Aludimos que ainda na década de 1960, mais precisamente em 1965 (HERHOLZ, 2020; SPIETH GYMNASTICS, 2020), os construtores de aparelhos Richard Reuther e Rudolf Spieth construiriam as barras paralelas assimétricas no modelo de duas barras fixas dispostas em altura diferentes, conectadas por reguladores de distância, as quais eram estabilizadas por cabos de aço e correntes. Esse aparelho, que constitui a base do atual, foi utilizado pela primeira vez no Campeonato Europeu em Amsterdam no ano de 1967.

Por fim, no período analisado no estudo, observamos que as grandes estrelas desse aparelho eram mulheres adultas que estavam à frente do seu tempo ao ditarem os movimentos nas barras paralelas assimétricas, algo que se contrasta à tendência de atletas jovens na atualidade. Essas ginastas estavam em busca de algo específico e que demarcasse seu espaço na GA, e mostraram por meio de suas séries que não bastava um aparelho adaptado, ou seja, emprestado do masculino. 
Corroboramos Scharenberg (2008) que todas essas mudanças exibem a determinação em legitimar as mulheres em um cenário tradicional e masculino, que caracterizavam a modalidade.

\section{REFERÊNCIAS}

ADELMAN, Miriam. Mulheres no esporte: corporalidades e subjetividades. Movimento, v. 12, n. 1, p. 11-29, 2006. Disponível em: https://periodicos.ufsc.br/index.php/motrivivencia/article/view/77755/45716. Acesso em: 30 mar. 2021.

ALMEIDA, Célia Sales de. Feminismo negro: luta por reconhecimento da mulher negra no Brasil. Belo Horizonte: Dialética, 2020.

ALONSO, Luisa Klein. Mulher, corpo e mitos no esporte. In SIMÕES, Antonio Carlos (org.) Mulher e esporte: mitos e verdades. São Paulo: Manole, 2003. p.1-33

ANDRADE, Maria Margarida de. Introdução à metodologia do trabalho científico. 10. ed. São Paulo: Atlas, 2018.

AYKROYD, Peter. Modern gymnastics. Nova York: Arco Publishing, 1985.

BRANDÃO, Maria Regina Fátima; CASAL, HiranValdes. Mulheres-atletas e o esporte de rendimento: a questão de gênero. In SIMÕES, Antonio Carlos. (org.). Mulher e esporte: mitos e verdades. Barueri: Phorte, 2003. p. $155-163$

CARAVALHO, Joana Machado Bastos Rodrigues. Um estudo comparativo entre os elementos técnicos da barra fixa e paralelas assimétricas entre 1987 e 2003. 148f. Dissertação (Mestrado em Ciência do Desporto) - Faculdade de Ciência do Desporto e de Educação Física, Universidade do Porto, Porto, 2004.

COMITATO ORGANIZZATORE DEI GIOCHI DELLA XVII OLIMPIADE. Gymnastique - gymnastics ginnastica: règlement - regulations. Roma: ComitatoOrganizzatore, 1960

COMITE D'ORGANISATION DES JEUX DE LA XVIII OLYMPIADE. Reglement de gymnastique. Tóquio: Comité d'organisation, 1963.

DEVIDE, Fabiano Pries. Gênero e mulheres no esporte: história das mulheres nos Jogos Olímpicos Modernos. Ijuí: Ed. Unijuí, 2005.

EXECUTIVE COMMITTEE AMSTERDAM. Gymnastics. Amsterdam: N. V. Van Munster's Drukkerijen, 1928

FREDERICK, A. Bruce. Gymnastics in physical education. The Modern Gymnast, v. 4, n. 8, p. 25, 1962.

GLASS, Laurie K. Historical research. In BRINK, Pamela J.; WOOD, Marilynn J. (orgs).Advanced design in nursing research. Newbury Park: SAGE, 1989. p. 183-200.

GODOY, Arilda Schmidt. Pesquisa qualitativa: tipos fundamentais. Revista de Administração de Empresas, São Paulo, v. 35, n. 3, p. 20-29, 1995. Disponível em: https://www.scielo.br/scielo.php?script=sci arttext\&pid=S0034-75901995000300004. Acesso em: 30 mar. 2021.

GOEHLER, Josef. Highlights of women's olympic gymnastics. In: STRAUS, Hal. (ed.). Gymnastics guide. Mountain View: World Publications, 1978. p. 16-19. 
GOODBODY, John. Illustrated history of gymnastics. Londres: Stanley Paul \& Co., 1982.

GRESSLER, Lori Alice. Introdução à pesquisa: projetos e relatórios. São Paulo: Loyola, 2003.

GUTMAN, Dan. Gymnastics. Penguin Books: London, 1996.

GUTTMANN, Allen. Women's sports: a history. Nova York: Columbia University Press, 1991.

HAGELIN, Ove. (comp.). Kinetic jottings: rare and curious books in the library of the old Royal Central Institute of Gymnastics. An illustrated and annotated catalogue. Estocolmo: Idrottshögskolans Bibliotek. 1995.

HERHOLZ, Eckhard. History of the uneven bars.2003. Disponível em:

http://www.gymmedia.com/Anaheim03/appa/unevenbars/history ub e.htm. Acesso em: 10 out. 2020.

HUGUENIN, Andre. 100 years of the International Gymnastics Federation: 1881 - 1981. Montier: FIG, 1981.

ISAAC, Stephen; MICHAEL, William Burton. Handbook in research and evaluation: a collection of principles, methods, and strategies useful in the planning, design, and evaluation of studies in education and the behavioral sciences. San Diego: EdITS, 1981.

JALADE-LAFOND, Guillaume. Recherches pratiques surlesprincipalesdifformitésducorpshumain et surlesmoyens d'y remédier. Paris: J.-B. Baillière, 1829.

KAIMAKAMIS, Vasilios; PAPADOPOULOS, Panagiotis; KAIMAKAMIS, Dimitrios; DUKA, Stella. Invention and evolution of the parallel bars in the first half of the 19th century. Studies in Physical Culture \& Tourism, v. 17, n.2, p. 167-172, 2010. Disponível em: https://www.wbc.poznan.pl/publication/127721. Acesso em: mar. 2021.

KERR, Roslyn. The evolution of women's artistic gymnastics since 1952. 392f. Dissertação (Mestrado em Educação). University of Sydney, Sydney, Austrália, 2003.

LEAVY, Jane. The battle against time and gravity. In: SMITH, Lissa (org.). Nike is a goddess: the history of women in sports. p. 221-241.

LOURO, Guacira Lopes. Gênero, sexualidade e educação: uma perspectiva pós-estruturalista. Petrópolis: Vozes, 1997.

MATEJSKI, Myrtle P. Ladies' aid societies and the nurses of Lincoln's army. Journal of Nursing History, v. 1, p. 35-51, 1986. Disponível em: https://pubmed.ncbi.nlm.nih.gov/11620935/. Acesso em: 30 mar. 2021.

MATTERN, Joanne. Gymnastics: uneven parallel bars. Rourke Corporation: Florida, 1999.

NELSON, Mariah Burton. Introduction: who we might become. In SMITH, Lissa. (org.).Nike is a goddess: the history of women in sports. p. ix-xv.

NOTTER, Lucille Elizabeth. The case for historical research in nursing. Nursing Research, v. 21, n. 6, p. 483. 1972. Disponível em:

https://journals.1ww.com/nursingresearchonline/Citation/1965/01410/THE_CASE_FOR_HISTORICAL_RE SEARCH.7.aspx. Acesso em: 30 mar. 2021.

OLIVEIRA, Mauricio Santos; BORTOLETO, Marco Antonio Coelho. O código de pontuação da ginástica artística masculina ao longo dos tempos. Journal of Physical Education, v. 20, n. 1, p. 97-107, 2009. 
Disponível em: http://www.periodicos.uem.br/ojs/index.php/RevEducFis/article/download/5885/3991/. Acesso em: 30 mar. 2021.

OLIVEIRA, Rosemeire; POLIDORO, Daniel José; SIMÕES, Antonio Carlos. Perspectivas de vida e transição de carreira de mulheres-atletas de voleibol. In: SIMÕES, Antonio Carlos (org). Mulher e esporte: mitos e verdades. São Paulo: Manole, 2003. p.177-191.

ORGANISATIONSKOMITEE FÜR DIE XI. OLYMPIADE BERLIN 1936. Official report: gymnastics. v. 2. Berlim: Wilhelm Limpert, 1937.

ORGANISING COMMITTEE FOR THE XVTH OLYMPIC GAMES HELSINKI 1952. Gymnastics. Helsinki: Organising Committee, 1952

PALKA, Magdalena Zmuda; SIWEK, Matylda. Large scale gymnastic festivals (pan-sokol slets): the greatest social movement on polish territory prior to the first world war. The International Journal of the History of Sport, v. 35, n. 14, p. 1428-1443, 2018. Disponível em:

https://www.tandfonline.com/doi/abs/10.1080/09523367.2019.1597712. Acesso em: 30 mar. 2021.

PFISTER, Gertrud. As mulheres e os jogos olímpicos: 1900-97. In: DRINKWATER, Barbara Lee. (org.). Mulheres no esporte. Rio de Janeiro: Guanabara Koogan, 2004. p. 3-15.

PFISTER, Gertrud. Women's sports. LEVINSON, David; CHRISTENSEN, Karen.(org.).Encyclopedia of world sport: from ancient times to the present. Oxford: Oxford Press, 1999. p. 442-457.

PHILLIPS, Harry. Memo from the publisher. Sports Illustrated, v. 6, n. 2, p. 2-4, 1957. Disponível em: https://vault.si.com/search?query=1957. Acesso em: 30 mar. 2021.

PORTER, David. Winning gymnastics for girls. Nova York: Facts On File Inc., 2004.

PRESTIDGE, Jim. The love of gymnastics. New York: Crescent books, 1979.

PUBLIO, Nestor Soares. Evolução histórica da ginástica olímpica. $2^{\mathrm{a}}$ ed, São Paulo: Phorte, 2002.

RICHARDSON, Roberto Jarry. Pesquisa social: métodos e técnicas. São Paulo: Atlas, 1999.

SABADSÁG. Nyolcvanötéves Korondi Margittornász. 2020. Disponível em:

http://szabadsag.ro/-/nyolcvanot-eves-korondi-margit-tornasz. Acesso em: 10 out. 2020.

SANDS, Bill; CONKLIN, Mike. Everybody's gymnastics book. Nova York: Charles Scribner's Sons, 1984.

SCHARENBERG, Swantje. Uneven bars revolution: a matter of one idea and gender? In: ICOHTEC, 2008, Victoria, Anais eletrônico. Disponível em: http://icohtec.uvic.ca/abstracts.php. Acesso em: 12 dez. 2008.

SILVA, Carolina Rodrigues Freitas. Feminismo e discursos jornalísticos sobre o aborto. Boa Vista: Editora da UFRR, 2018.

SIMÕES, Antonio Carlos. A mulher em busca de seus limites no esporte. In: SIMÕES, Antonio Carlos. (org.). Mulher e esporte: mitos e verdades. Barueri: Manole, 2003. p. 1-33

SIMÕES, Antonio Carlos; CONCEIÇÃO, Paulo Felix Marcelino; NERY, Maria Aparecida Câmara. Mulher, esporte, sexo e hipocrisia. In SIMÕES, Antonio Carlos; KNIJNIK, Jorge Dorfman (org.). O mundo

psicossocial da mulher no esporte: comportamento, gênero, desempenho. São Paulo: Aleph, 2004. p. 61-86 
SIMONOV, Yevgeni. Symphony of grace: olympic gymnast Polina Astakhova. USSR, v. 53, n. 2, p. 64-65, 1961. Disponível em: https://www.google.com.br/books/edition//b2zJ0imx91kC?hl=en\&gbpv=1. Acesso em: 30 mar. 2021.

SPIETH GYMNASTICS. Invented by Spieth. Disponível em: https://www.spieth-gymnastics.com/invented_by_spieth-spieth-en/. Acesso em: 12 out. 2020.

TAKEMOTO, Masao; HAMADA, Seiichi. Illustrated women's gymnastics. Tóquio: Banyu Shuppan, 1958.

THE ORGANISING COMMITTEE FOR THE XIV OLYMPIAD LONDON 1948. Gymnastics. Londres: Organising Committee, 1948.

TONRY, Don; TONRY, Barbara. Sports illustrated: women's gymnastics. 2 v. Nova York: Lippincott \& Crowell, 1980.

\section{NOTAS DE AUTOR}

AGRADECIMENTOS - Não se aplica.

CONTRIBUIÇÃO DE AUTORIA

Concepção do manuscrito: M. S. Oliveira, A. S. S. Souza, M. Nunomura

Coleta de dados: M. S. Oliveira, A. S. S. Souza, M. Nunomura

Análise de dados: M. S. Oliveira, A. S. S. Souza, M. Nunomura

Discussão dos resultados: M. S. Oliveira, A. S. S. Souza, M. Nunomura

Produção do texto: M. S. Oliveira, A. S. S. Souza, M. Nunomura

Revisão e aprovação: M. S. Oliveira, A. S. S. Souza, M. Nunomura

\section{FINANCIAMENTO}

Fundação de Amparo à Pesquisa e Inovação do Espírito Santo - FAPES

Número FAPES: 128/2017

\section{CONSENTIMENTO DE USO DE IMAGEM}

A imagem foi adaptada e referenciada no texto do artigo.

APROVAÇÃO DE COMITÊ DE ÉTICA EM PESQUISA - Não se aplica.

CONFLITO DE INTERESSES - Não se aplica.

\section{LICENÇA DE USO}

Os autores cedem à Motrivivência- ISSN 2175-8042 os direitos exclusivos de primeira publicação, com o trabalho simultaneamente licenciado sob a Licença CreativeCommonsAttribution Non-Comercial ShareAlike (CC BY-NC SA) 4.0 International. Esta licença permite que terceirosremixem, adaptem e criem a partir do trabalho publicado, desde que para fins não comerciais, atribuindo o devido crédito de autoria e publicação inicial neste periódico desde que adotem a mesma licença, compartilhar igual. Os autores têm autorização para assumir contratos adicionais separadamente, para distribuição não exclusiva da versão do trabalho publicada neste periódico (ex.: publicar em repositório institucional, em site pessoal, publicar uma tradução, ou 
como capítulo de livro), com reconhecimento de autoria e publicação inicial neste periódico, desde que para fins não comerciais e compartilhar com a mesma licença.

\section{PUBLISHER}

Universidade Federal de Santa Catarina. Programa de Pós-Graduação em Educação Física. LaboMídia - Laboratório e Observatório da Mídia Esportiva. Publicado no Portal de Periódicos UFSC. As ideias expressadas neste artigo são de responsabilidade de seus autores, não representando, necessariamente, a opinião dos editores ou da universidade.

\section{EDITORES}

Mauricio Roberto da Silva, Giovani De Lorenzi Pires, Rogério Santos Pereira.

\section{EDITOR DE SEÇÃO}

Rogério Santos Pereira

\section{REVISÃO DO MANUSCRITO E METADADOS}

João Caetano Prates Rocha; Keli Barreto.

\section{HISTÓRICO}

Recebido em: 22 de outubro de 2020.

Aprovado em: 10 de março de 2021. 